\title{
Enlightenment of Bourdieu Cultural Capital Theory
}

\author{
Yongjian Xu \\ Jilin Agricultural University \\ School of Marxism \\ Changchun, China 130118
}

\author{
Liqun $\mathrm{Xu}$ \\ School of Foreign Languages \\ Capital University of Economics and Business \\ Beijing, China 100026
}

\begin{abstract}
Bourdieu's cultural capital theory is one of the important contents of his sociology theory system. Cultural capital contains three forms, namely specific cultural capital, objective cultural capital and institutionalized cultural capital. Cultural capital theory enriches and develops Marx's cultural theory and it is worth being referred to by today's ideological and political education in China to some extent.
\end{abstract}

Keywords-cultural Capital Theory; Bourdieu; sociology theory system

\section{INTRODUCTION}

As the father of sociology, Kong De puts forward the concept of cultural capital in Social Regime System, which is the initial sprout of cultural capital. French sociologist Bourdieu puts forward cultural capital theory in a relative systematic way and interprets cultural capital in a noneconomics way, breaking through previous explanations about capital. Bourdieu divides the whole society into many "fields" which connect with and influence each other. In different "fields", capital is divided into different forms, mainly including economic capital, cultural capital, social capital and so on. This kind of division extremely expands people's understanding of capital.

\section{Bourdieu's CUltural CAPITAL THEORY}

Bourdieu thinks that cultural capital consists of the two major elements of culture and capital. The so-called "culture" belongs to physiological concept, referring to social ideology, its materialized embodiment and behavior, and life style. The so-called "capital" is economics concept, referring to capital used for appreciation. In the concept of cultural capital, culture is the subject and capital is a kind of attached property of relevant culture. Cultural capital is Bourdieu's cultural explanation of capital. Cultural capital is a kind of certain ideology, behavior mode and life style. It is also a kind of cultural resource which can breed new culture and promote appreciation of cultural resource. Culture is also a kind of capital which can bring about increment of value.

Bourdieu does not give a clear definition to cultural capital. He thinks that cultural capital is a kind of cultural resource in form and the accumulation of people's labor achievements in essence. Cultural capital exists in three forms:

- The first is specific display form of cultural capital, namely it exists in the form of everlasting "temperament" in spirit or in body. Cultural capital in a specific form can be called cultural competence. "Obtaining of individual cultural competence is based on internalization. During the process, it is necessary to learn and invest time and to do it yourself. There is no alternative principle." Cultural capital in a specific form is closely connected with certain social individuals. This kind of cultural capital can not be obtained through buying, exchanging and so on. Instead, you have to do it yourself. And this kind of cultural capital disappears with vanishing of individual. This kind of cultural capital can only be obtained through family education and school education. Once social individualized cultural capital is obtained, it becomes people's fixed wealth and cultural quality of a social individual. This kind of quality determines social individual's cultural competitiveness.

- The second is objective performance of cultural capital. Cultural capital is "displayed in the form of cultural products(poetry, books, pictures, film and television, etc.). These products are traces left by theory or specific manifestation of theory or criticism of these theories and problems and so on". This is cultural capital in an objective form, namely cultural products. Cultural product's value is given by social individuals with cultural competence according to its cultural internalization. Cultural products usually exist in material form with certain economic value and they can be transferred and exchanged. Therefore, cultural products are special commodities in market, namely cultural commodities. Particularity of cultural commodity both displays its materiality and symbolism. In the aspect of material expression, cultural commodity has economic value. In the aspect of symbolism expression, cultural commodity represents cultural capital's cultural value.

- The third is system performance of cultural capital, namely "a kind of objectification form which has to be treated differently. Because this kind of form gives cultural capital a kind of completely primitive capital. And cultural capital is exactly protected by this property." Institutionalized cultural capital is the existing form of social subject's cultural competence after obtaining qualification authorized by social cultural system. Social cultural management department intervenes and controls cultural capital through institutionalization of cultural capital to make cultural capital become a kind of privilege generally 
accepted by the society and to make cultural capital holders enjoy this kind of privilege. Institutionalized cultural capital is institutional qualification and status obtained by subject in a certain cultural system. Among them, the most typical one is education background and professional certification. This kind of education background and professional certification gives its owners a kind of legal value. The higher the grade of academic certificate and vocational qualification certificate is, the greater owner's cultural capital quantity is and the stronger owner's cultural competence.

Cultural capital is a kind of accumulation of cultural value and it can be transformed into people's wealth in the actual world. Cultural capital can flow and can form commodities with both cultural value and economic value. This kind of situation is the result of rapid development of today's society and economy. Here, people not only emphasize on economic value of commodity itself, but also emphasize more on extra value brought by adding of cultural element. Therefore, current economic development has transformed from commoditycentered to people-centered. Socio-economic increment should not only consider tangible material capital, but also consider importance of intangible cultural capital.

\section{Visual Field Of MARX CUltuRAL CAPITAL RESEARCH}

In The Capital Theory, Marx puts forward: Capital is a kind of value which can rely on its own operation and development to create new value and finally realize increment of its own value. It is "a kind of relation of social production and it is production relation of capitalism." It "not only includes means of livelihood, instruments of labor, material and material products, but also includes exchange value. All products included in capital are commodities." Marx deeply analyzes and criticizes internal development logic in capital itself from "commodity fetishism" and further explains comprehensive alienation reality of society rooted in capital alienation in capitalist society. He further clarifies comprehensive alienation relationship between capital and human, human and labor, human and labor product, and human and human themselves, revealing the deep relationship of capital leading human to materialization and commercialization. Therefore, it is not difficult for us to understand that capital is a special expression form of certain production relation and it is historical.

Development essence of cultural capital is capital breaking spiritual limit and rapid expanding to cultural field. This kind of cultural capitalization is an necessary phase of generation and development of cultural capital.

Marx points out: "Only capital can create bourgeois society and social members' general occupation of nature and social bond." Capital can expand uninhibitedly and has extreme destructiveness at the same time. On the one hand, it destroys feudal society's economic order, emancipates social productivity and pushes forward development of social politics, economy, culture and so on. On the other hand, it intensifies materialization and commercialization of human and general alienation of the whole society, making development of society and human in a twisted one-dimensional state. In Marx's view, society is "a social organism where all relations exist at the same time and rely on each other". Based on research on material production, spiritual production and human's own production relation and systematic clearing up of previous social relations, he comprehensively and systematically elaborates and analyzes social organism thought. It is also Marx's and Engels' enrichment and development of culture development theory, having important historical status. At the same time of objectively affirming important social status of culture, Marx deeply reveals interaction and interdependency dialectical relationship of various elements in culture development.

As to culture research, Marx mainly starts from "realistic men and their practice" to explore cultural view. He takes social material production as the logic starting point and basis of cultural research. In Marx's point of view, the essence of ordinary labor is "firstly the process between human and nature and then material exchange process of human and nature aroused, adjusted and controlled by human's own activities." It is realistic social productivity in social development, representing the most objective productivity level in society. Production relations refer to various social relations between human and other labor producers in the process of carrying out various specific laboring. According to specific analysis and research on the above a series of theory and current situation, Marx systematically summarizes the law that production relation has to be fit for development status of productivity and supper structure has to be fit for economic situation. It is easy to find out that Marx's The Capital Theory provides "the solidest fact" basis for his cultural view and endows Marx's cultural view with the essence of scientificity. As a necessary phase of development of human society, we have to understand capital in a dialectical and scientific way, objectively evaluate its negative and positive effect in social and historical development, and take the same cognition attitude towards cultural capital in development of modern society.

\section{ENLIGHTENMENT OF BOURDIEU'S CULTURAL CAPITAL THEORY}

Compared with Marx's classical capital theory, Bourdieu's cultural capital theory belongs to new capital theory. Both classical capital theory's and new capital theory's cultural capital intangibly brings multiple benefits to everyone in various material forms. At this point, they two are interlinked.

\section{A. Enrich and Develop Marx's Cultural Theory}

Marx's cultural theory takes commodity, capital and so on as base points to deeply reveal extremely evil capitalism system. However, Bourdieu's cultural capital is not the same. In Bourdieu's point of view, social chances are not equal and distribution of capital in society is not equal. Bourdieu also reveals the situation of people exploiting people in cultural capital and uncovers the essence of social life. As a kind of exclusive resource, cultural capital has different functions in different social resources and rights allocation circumstances. But the same point is that it serves currently existed social 
superstructure. According to unequal allocation of cultural resource, each person is subjected to different social treatments in social competition due to obtaining different cultural resources. Human take ruling class as service object and satisfy and realize ruling class's social benefit and personal value to the maximum. Therefore, it is displayed as a kind of unequal relationship between human or phenomenon as a whole in class society. Through deepening research on sociology, Bourdieu's cultural capital reproduction theory deeply reflects the special law of production and reproduction in capitalist society. The reproduction is the sum of cultural reproduction and economic reproduction and it pushes forward self production of social structure of the whole capitalist society.

\section{B. Create A New Perspective for Sociology Research}

Relationship between an individual and society is the key point pointed out by cultural capital theory. It expands and develops research field of modern economics, carries out interscientific research according to the major direction of future scientific research development, and provides sociology with relationship between subject and society with a brand new foothold.

Analysis frame of cultural capital creates a brand new view for our research. It clearly shows us the innovative perspective, thus deeply intensifies people's attention to and emphasis on individual cultural capital, material cultural capital, system cultural capital and many other cultural capital forms and makes people objectively know significant positive influence of cultural capital on national development and realization of personal social value and so on.

Research and analysis on cultural capital plays an important pushing role in intensification and promotion of theoretical value in other relevant researches. "As a new concept and term, cultural capital has new connotations in two aspects: The first is that it enlarges extension of the concept of capital in economics sense and enriches connotations of the concept of capital. The second is that it regards expression form of some cultural capital as constitutional elements of society structure as a kind of capital." 5 It makes many structural elements needed by composition and development of society clear and brief and makes concept of cultural resource, cultural industry, cultural system and so on show new connotations. All these bring higher theoretical value to research on social structure and so on. Therefore, deep research on cultural capital has important guiding function on our deep research on cultural resource allocation, cultural industry development, cultural system constructing and so on.

\section{Make Modern Sociology Get Rid of Constraint from Rational Economic Person Assumption in Economics}

It mainly unfolds in two aspects: Firstly, it helps culture get rid of the "myth" status of rejecting using scientific analysis to research sacred field culture. Secondly, it displays homology of structures of cultural capital rank and social rank. Appearance of cultural capital theory widens people's understanding of culture's narrow-mindedness and destroys culture's "nonprofit" status in concept. It makes people start to pay attention to its existence and function everywhere in daily life, making social status, power, class and social reproduction closely related with each other internally. It breaks the viewpoint that social culture of capitalist is nonprofitable. The essence of constant production and reproduction of culture in society is re-appreciation and reproduction of cultural capital. Among them, there exists reproduction of privilege, unequal ruling class and privileged stratum habit. Bourdieu's cultural capital reproduction theory is extremely unique. Wealthy people get richer and poor people get poorer, which is deep revealing of and criticism on various current unequal situations in social reproduction in essence. It will result in that only prominent ruling class and privileged stratum in social economy among the whole class society can fundamentally realize benefit in multiple aspects at last. The root is that economic and cultural development in class society is to satisfy and consolidate benefit of ruling class. Thus, they have natural advantages in development.

\section{Reveal Important Power of Modern Social Economic Growth}

Cultural capital plays an important role in personal or group's acquisition of profit. Cultural capital theory also deeply reveals the following conclusion. In modern society, when currency is popular in economic behavior, economic purpose retreats from historical stage. And cultural purpose will take the place of economic purpose in social and historical development. Because economic development can not do without internal spiritual support. Without culture, economic development would not be long. Nowadays, with rapid development of modern social economy and culture, people know and discover value of cultural capital more clearly, which is due to cultural capital theory. Because culture is the internal power for economy to constantly develop rapidly. When economic development reaches a certain phase and social economic capital gets abundant, it is certain that economy will feed culture in turn. In composition of the whole social capital, the proportion of cultural capital gets higher and higher. Cultural capital will push forward general development of social economy and comprehensive development of human society in a wider level.

In addition, the cultural capital theory put forward by Bourdieu has important significance to China's education development. Capital is accumulative living labor. Once the social living labor or general labor is accumulated in great quantities and is occupied personally by a part of social members, this part of the group obtains the privilege of preemption of social resource. Therefore, in this sense, education is an important means to obtain cultural capital and an important channel for modern college students to improve their own cultural quality and cultural value, having important influence on and significance to ideological and political education of college students.

\section{REFERENCES}

[1] Bao Yaming. Cultural Capital and Social Alchemy[M]. Shanghai: Shanghai People's Publishing House, 1997. 
[2] Chen Feng. Cultural Capital Introduction[D]: [Doctorate thesis]. Beijing: Central Party School, 2005.

[3] Zhang Zhihao. Discussion on Cultural Capital[D]: [Master's thesis]. Fuzhou: Fujian Normal University, 2007. 